\title{
Level of acuity in pediatric patients with recurrent emergency department visits
}

\author{
Ilene Claudius, Chun Nok Lam \\ LAC+USC, Department of Emergency Medicine, Keck School of Medicine, USA \\ Correspondence: Ilene Claudius. Address: LAC+USC, Department of Emergency Medicine, Keck School of Medicine, \\ USA. E-mail: iaclaudius@gmail.com
}

Received: July 9, 2012

DOI : $10.5430 /$ jha.v1n2p1

Accepted: August 20, 2012

URL: http://dx.doi.org/10.5430/jha.v1n2p1
Published: December 1, 2012

\section{Abstract}

Introduction: Recurrent ED utilizers account for a substantial proportion of ED visits, yet little data exists on children with multiple visits. The objective of this study was to compare the need for interventions and triage acuity of recurrent utilizers of a pediatric emergency department to that of non-recurrent utilizers.

Methods: This is a retrospective analysis of children presenting to a pediatric emergency department. Children were classified as recurrent utilizers if they had 4 or more visits to the ED per year and non-recurrent utilizers if they had less than 4 visits. Data was collected and inter-group comparison performed on critical interventions received (admission, consultation, intravenous fluid therapy, observation, and performance of procedures), all interventions received (including critical interventions as well as laboratories, radiographs, and medications), and triage acuity for the index visit.

Results: Two-hundred thirty patients were included, of whom, 15\% were classified as recurrent utilizers. This group had significantly lower rates of requiring a critical intervention (85.9\% vs. 50\%, $p=.001$ ), lower rates of any intervention (37\% vs. $74.5 \%, p=.007$ ), and less urgent triage acuity (3.3 vs. 3.1, $p=.025)$.

Conclusions: Recurrent utilizers of the pediatric emergency department had significantly lower need for intervention and less urgent mean triage acuity when compared with non-recurrent utilizers.

\section{Key words}

Emergency department, Recidivism, Intervention, Triage acuity

\section{Introduction}

Emergency department (ED) recidivism is often defined as 4 or more visits per year ${ }^{[1]}$. Recurrent users account for approximately $25 \%$ of visits to an ED ${ }^{[2]}$. Repeat Pediatric ED (PED) utilizers are more likely to have at least 1 admission ${ }^{[3]}$. Top adult ED utilizers often receive high triage scores ${ }^{[4]}$. However, in adult studies, mortality amongst patients attending the ED 4-5 times per year is lower than in those with a single ED visit ${ }^{[5]}$.

Several factors have been shown predictive of ED recidivism in a pediatric population, including patient age, race, diagnosis ${ }^{[6]}$, distance from hospital, parental worry, precarious socioeconomic/family situation, and insurance type ${ }^{[3]}$. Parents who are themselves recurrent ED visitors are more likely to bring their children to the ED for repeat visits ${ }^{[7]}$. 
Publically insured children are more likely overall to have an ED visit, particularly for a non-urgent condition, than uninsured or privately insured children, yet this difference is not significant when covariates are considered ${ }^{[8]}$.

Different markers have been used to assess for the illness acuity in ED patients, including triage level, admission, and number of interventions received. Our primary goal was to assess the difference in acuity level of patients who use the PED recurrently compared with patients who are not recurrent ED users by using the patients' need for a critical intervention (admission, specialty consultation, observation, intravenous fluid therapy, or performance of a procedure) as a marker of acuity level. We hypothesized that recurrent utilizers of the PED would require fewer interventions than non-recurrent utilizers. Secondary outcomes studied included the need for any intervention and a difference in triage level.

\section{Methods}

\subsection{Study setting and population}

This study was performed at an urban ED with a dedicated PED from March 2011 through September 2011. This is part of a larger study, and patients included represent the age-matched control group consecutively selected on randomly assigned 24 hour periods within this time frame.

\subsection{Study design}

This is a retrospective analysis. Once patients were identified from the tracking board, a data sheet was completed to record demographic information, triage acuity, interventions, and disposition. The electronic medical record system was then queried for number of visits between the initiation of the EMR system in 7/2009 and 6/2012. As some patients were born during this time period, the average number of visits per year was calculated, after adjustment for the years of life during the study enrollment period. These visits were individually examined for any indication of the presence of a chronic illness. Patients with incomplete charts available in the computer were eliminated. Laboratory and radiology records were reviewed as well to insure thoroughness of data collection. This study was approved by the local Institutional Review Board.

\subsection{Outcome measures/ definitions}

"Recurrent ED users" were defined as patients with 4 or more visits/year, averaged over the study period; thus patients were split into 2 groups: recurrent ED utilizers and non-recurrent ED utilizers. Our primary outcome measure was the need for any "critical intervention" in the ED, which was defined as a hospital admission, planned observation of 6 hours or greater, subspecialty consultation, administration of intravenous fluids, or performance of a procedure (e.g. suturing, urinary catheterization, splinting). Secondary outcomes included: 1) performance of any intervention, including the critical interventions listed above, as well as interventions most primary care offices have available (medication administration, laboratories, radiographs, or prescription medications administered at home). 2) triage acuity using the ESI (Emergency Severity Index) triage system in which 1 represents most urgent and 5 least urgent. Combined, these outcome measures include most studies' definition of urgent vs. non-urgent visits ${ }^{[9]}$.

\subsection{Data analysis}

The 2 groups were compared by chi-squared for the number of critical interventions and the number of total interventions. Patients with chronic illnesses were used in the sample but data is also reported separately on this subgroup. Proportion in each triage acuity group was compared by fisher exact test, and overall means were compared by Mann-Whitney U. 


\section{Results}

Two-hundred forty-eight patients were identified, of whom 18 were excluded ( 9 for not matching a patient $<18$ years, 9 for incomplete records), leaving 230 patients in that group. Patient demographics are detailed in Table 1 , and the nature of the chief complaints at the index visit is in Table 2 . Patients with chronic conditions comprised $11.7 \%$ of the overall sample, of which 57\% had asthma. Number of total visits ranged from 1 to 29, with an average of 3.94 .

Table 1. Demographic Information of Patients

\begin{tabular}{|c|c|c|c|c|}
\hline & $\begin{array}{l}\text { Overall } \\
(\mathrm{N}=230)\end{array}$ & $\begin{array}{l}\text { Recurrent Users } \\
(\mathrm{n}=35)\end{array}$ & $\begin{array}{l}\text { Non-Recurrent } \\
\text { Users }(n=195)\end{array}$ & $\boldsymbol{P}$ \\
\hline Age in years (mean) & 5.5 & 2.3 & 6.0 & $<.001$ \\
\hline Gender (\%) & & & & .04 \\
\hline Female & 47 & 29 & 49 & \\
\hline Male & 53 & 71 & 51 & \\
\hline Latino (\%) & 93 & 97 & 92 & .479 \\
\hline Presentation Time (\%) & & & & .517 \\
\hline 7AM - 3РM & 29 & 36 & 28 & \\
\hline 3PM - 11PM & 44 & 36 & 45 & \\
\hline 11PM - 7AM & 27 & 28 & 27 & \\
\hline Insurance Type (\%) & & & & .035 \\
\hline Private & 5 & 3 & 6 & \\
\hline State-Sponsored & 79 & 94 & 76 & \\
\hline None & 16 & 3 & 18 & \\
\hline Chronic Medical Condition (\%) & 12 & 12 & 11 & 1.000 \\
\hline
\end{tabular}

*Wilcoxon Rank Sum Test and Fisher's Exact Test were used to calculate $P$-values

Table 2. Nature of chief complaints

\begin{tabular}{ll}
\hline Item & Percentage (\%) \\
\hline Fever & 20.5 \\
Trauma & 19.6 \\
Abdominal Pain & 10.0 \\
Other ENT Complaints & 8.4 \\
Upper respiratory Tract Infection & 8.4 \\
Other GI Complaints & 7.3 \\
Exacerbation of Chronic Disease & 2.4 \\
Other Respiratory/Cardiac Symptoms & 2.4 \\
Other & 20.5 \\
\hline
\end{tabular}

Overall, $19 \%$ of patients were admitted, $32.5 \%$ of patients received a critical intervention, and $71 \%$ of the patients received any intervention. The most commonly required interventions in both groups were use of imaging, laboratories, and prescription medications. Mean triage acuity was 3.1. In the overall sample, ESI triage levels 1, 2, 3, 4 and 5 were assigned to $0.9 \%, 17 \%, 56 \%, 24.8 \%$ and $2.2 \%$ respectively.

Of the sample, 14.8\% qualified as "recurrent ED users". In this group, 2 (5.9\%) of patients were admitted, 5.9\% received a critical intervention, 50\% received any intervention, and the mean triage acuity was 3.32 (95\%CI 3.1-3.55). Of the 2 patients admitted, 1 had a chronic underlying medical condition (chronic lung disease), and the other did not. The 
remaining $85.2 \%$ were not recurrent utilizers. In the group of non-recurrent ED users, $18.9 \%$ of patients were admitted, $37 \%$ of patients received a critical intervention, $74.5 \%$ of the patients received any intervention, and the mean triage acuity was 3.05 (95\%CI 2.95-3.15). Recurrent ED users were less likely to have received any critical intervention ( $p=0.001$ ), or any intervention ( $p=0.007)$, than non-recurrent ED users. Recurrent ED users also demonstrated a significantly higher mean triage score than recurrent ED users $(p=0.025)$, indicating a less urgent triage level. Table 3 provides an overall comparison of ESI levels and interventions between the groups.

Table 3. Overall Comparisons between Recurrent and Non-recurrent Users

\begin{tabular}{|c|c|c|c|}
\hline Variable (\%) & $\begin{array}{l}\text { Recurrent Users } \\
(n=34)\end{array}$ & $\begin{array}{l}\text { Non-Recurrent } \\
(n=196)\end{array}$ & $\bar{P}$ \\
\hline Triage Acuity & & & .151 \\
\hline 1 & 0 & 1.0 & \\
\hline 2 & 8.8 & 18.4 & \\
\hline 3 & 50.0 & 57.1 & \\
\hline 4 & 41.2 & 21.4 & \\
\hline 5 & 0 & 2.0 & \\
\hline Admission & & & .081 \\
\hline Admitted & 5.9 & 18.9 & \\
\hline Not-admitted & 94.1 & 81.1 & \\
\hline Intervention & & & .007 \\
\hline Yes & 50.0 & 74.5 & \\
\hline No & 50.0 & 25.5 & \\
\hline Critical ER Intervention & & & $<.001$ \\
\hline Yes & 5.9 & 37.0 & \\
\hline No & 94.1 & 63.1 & \\
\hline
\end{tabular}

For the 27 (11.7\%) patients with chronic illnesses, 4 (14.8\%) fell into the recurrent user group, and 23 (85.1\%) into the non-recurrent user, consistent with the breakdown of patients overall. Forty-eight percent of these patients were admitted, $48 \%$ of patients received a critical intervention, and $93 \%$ of the patients received any intervention. Their mean triage acuity was 2.7. Fifty-nine percent of patients with chronic illnesses suffered from asthma as their illness.

\section{Limitations}

This is a single-center group of patients from a county hospital serving a largely underinsured population. It is unlikely this data could be extrapolated to hospitals serving patients with primarily private insurance and close relationships with their primary care providers. Additionally, given the concentration of hospitals in Los Angeles, we could not realistically assess if patients returned to other EDs as well, possibly resulting in some recurrent utilizers being misclassified as non-recurrent utilizers. That said, $15 \%$ of our patients qualified as frequent utilizers, whereas prior studies have shown rates in the $4.5-8 \%$ range ${ }^{[1]}$, making it likely that we identified most. Very few patients in the group had repeat visits within 48 hours, though it is possible that inaccurate diagnosis or incomplete discharge instructions at an initial visit led to subsequent visits, rather than patient factors. While using the commonly accepted definition of 4 visits/year will likely minimize the impact of this limitation, a recent article has suggested a threshold of 7 visits to avoid misclassification ${ }^{[10]}$. This has not been widely adopted yet, but does highlight some of the current issues involved in defining this patient group.

\section{Discussion}

In our population, recurrent utilizers of the PED required significantly fewer critical interventions, fewer interventions overall, and had a lower average triage acuity. Many of these visits could have potentially been averted had contact with a 
primary care provider been possible. As recurrent utilizers by definition account for a higher number of ED visits, interventions to assist this group of patients toward utilization of appropriate primary care services may be a worthwhile intervention against ED overcrowding.

Programs that extend primary care office hours, expand office locations, and coordinate primary care have been shown to decrease overall ED visits by 8-fold, with no change in overall cost, as expanded primary care costs were offset by decreased ED utilization ${ }^{[11]}$. Children with a clear medical home, even those with asthma, tend to use that medical home, rather than the ED, for acute care needs ${ }^{[12]}$. Conversely, poor understanding of the disease and indications for medication use have been associated with more frequent ED visits ${ }^{[13]}$. In patients with anxiety, a case management approach has also been shown effective in decreasing ED visits and overall costs ${ }^{[14]}$, although in pediatric and adolescent mental health patients, those actively involved in mental health and social services visited the ED more often than those not involved ${ }^{[15]}$. Augmentation of primary care services for patients with or without chronic diseases is an important step in reducing recurrent utilization of the ED by pediatric patients with low acuity complaints.

\section{Conclusion}

Recurrent ED utilizers in this study were of lower acuity when compared to non-recurrent utilizers of a pediatric ED. Improving opportunities for non-ED care in this population might decrease ED visits while still offering an appropriate level of care.

\section{References}

[1] LaCalle E, Rabin E. Frequent users of emergency departments: The myths, the data, and the policy implications. Ann Emerg Med. 2010; 56: 42-28. PMid:20346540 http://dx.doi.org/10.1016/j.annemergmed.2010.01.032

[2] Hunt KA, Weber EJ, Showstack JA, et al (2006). Characteristics of frequent users of emergency departments. Ann Emerg Med. 2006; 48: 1-8. PMid:16781914 http://dx.doi.org/10.1016/j.annemergmed.2005.12.030

[3] Maugein L, Lambert M, Richer O, et al. Repeat visits to a pediatric emergency department. Arch Pediatr. 2011; 18(2): 128-34. PMid:21215600

[4] Dipietro BY, Kindermann D, Schenkel SM (2012). Ill, itinerant, and insured: the top 20 users of emergency departments in Balitmore city. Scientificworldjournal. 2012; 1-6. PMid:22606057 http://dx.doi.org/10.1100/2012/726568

[5] Safwenberg U, Terent A, Lind L. Increased long-term mortality in patients with repeated visits to the ED. Eur J Emerg Med. 2011; 17(5): 274-9. PMid:20555266

[6] LeDuc K, Rosebrook H, Rannie M, et al. Pediatric emergency department recidivism: demographic characteristics and diagnostic predictors. J Emerg Nurs. 2006; 32(2): 131-8. PMid:16580475 http://dx.doi.org/10.1016/j.jen.2005.11.005

[7] Mistry RD, Hoffmann RG, Yauck JS, et al. Association between parental and childhood emergency department utilization. Pediatrics. 2005; 115(2): e147-51. PMid:15687422 http://dx.doi.org/10.1542/peds.2004-1798

[8] Luo X, Liu G, Frush K, et al. Children's health insurance status and emergency department utilization in the United States. Pediatrics. 2003; 112(2): 314-9. PMid:12897280 http://dx.doi.org/10.1542/peds.112.2.314

[9] Tsai JC, Liang YW, Pearson WS. Utilization of emergency department in patients with non-urgent medical problems: patient preference and emergency department convenience. J Formos Med Assoc. 2010; 109(7): 533-42. http://dx.doi.org/10.1016/S0929-6646(10)60088-5

[10] Doupe MB, Palatnick W, Day S, et al. Frequent users of emergency departments: Developing standard definitions and defining prominent risk factors. Ann Emerg Med. 2012; 60(1): 24-32. PMid:22305330 http://dx.doi.org/10.1016/j.annemergmed.2011.11.036

[11] Wang C, Villar ME, Mulligan DA, et al. Cost and utilization analysis of a pediatric emergency department project. Pediatrics. 2005; 116(5): 1075-9. PMid:16263992 http://dx.doi.org/10.1542/peds.2004-2093

[12] Kempe A, Beaty B, Englund BP, et al. Quality of care and use of the medical home in a stat-unded capitated primary care plan for low-income children. Pediatrics. 2000; 105(5): 1020-8. PMid:10790457 
[13] Rodriguez-Martinez CE, Sossa MP, Castro-Rodriguez JA. Factors associated to recurrent visits to the emergency department for asthma exacerbations in children: implications for a health education programme. Allergol Immunopathol. 2008; 36(2): $72-78$. PMid:1879658 http://dx.doi.org/10.1157/13120391

[14] Kolbasovsky A, Reich L, Futterman R, et al. Reducing the number of emergency department visits and costs associated with anxiety: a randomized, controlled study. Am J Manag Care. 2007; 13(2): 95-102. PMid:17286529

[15] Goldstein AB, Frosch E, Davarya S. Factors associated with a six-month return to emergency services among child and adolescent psychiatric patients. Psychiatr Serv. 2007; 58(11): 1489-92. PMid:17978263 http://dx.doi.org/10.1176/appi.ps.58.11.1489 